\title{
From the Editor in Chief
}

\section{TENSIONS IN HUMAN-TECHNOLOGY RESEARCH}

\author{
Päivi Häkkinen \\ Finnish Institute for Educational Research \\ University of Jyväskylä, Finland
}

As I begin my tenure as editor in chief of Human Technology: An Interdisciplinary Journal of Humans in ICT Environments, I am pleased both personally and professionally to continue building the significance of this journal in the scientific literature of many research fields. The founding editor in chief, Professor Pertti Saariluoma, has contributed greatly to defining the basis for the scope of Human Technology. During his editorial tenure, the papers published in the journal have addressed a wide variety of questions related to human-technology research. Earlier issues of the journal have covered research on mobile communication, innovations, ICT and education, human technologies for special needs, games and smart environments, culture, creativity and technology, distributed leadership and on-line communities, design-use relationships, cognition and HCI, psychology of programming, and creativity in software design. This variety of fields and topics certainly illustrates the multidisciplinary nature of humantechnology research. In the inaugural issue of the journal, Professor Saariluoma stated that becoming familiar with the wide variety of questions at the intersection of humans and technology and the potential solutions demands exploration irrespective of the field of research (Saariluoma, 2005). Clearly, no single theory or particular approach will solve the totality of human-technology problems (e.g., the grand challenges or "wicked problems" in many societies). One of the guiding principles in multidisciplinary research, therefore, has been to foster and support openness towards multiple schools of thoughts (Stahl \& Hesse, 2011).

It is evident that multidisciplinary fields of research include theoretical and methodological diversity. For example, in the research field of computer-supported collaborative learning, ${ }^{1}$ no one particular theoretical view or analysis method defines the field; rather the object of the study, in this case some type of collaborative use of technology for teaching and learning purposes (Clarà \& Mauri, 2010), is the focus. To move ahead, then, researchers and publishers must account for alternative perspectives and dialogues as necessary prerequisites for any multidisciplinary field of research, such as computer-supported collaborative learning or humantechnology research in general. Moreover, the confrontation amid a diversity of viewpoints and the critique of established paradigms are typical for scientific revolutions. However, this diversity makes the articulation of theoretical perspectives, methodological choices, and research results complicated. According to Clarà and Mauri (2010), it is not the diversity itself that complicates

(C) 2012 Päivi Häkkinen and the Agora Center, University of Jyväskylä

URN:NBN:fi:jyu-201205141649 
multidisciplinary research, but rather the difficulty of positioning specific results within this diversity. Reliably identifying the theoretical and methodological tensions enables the dialectic development of different approaches to the field (Clara \& Mauri, 2010).

In addition to tensions between the different approaches and paradigms, the relation between scientific and practical perspectives remains in constant tension in human-technology research. Although the scientific community at large can regard many principles of human-technology research as highly promising, implementing them among broader communities of practitioners is challenging. As Professor Saariluoma stated in 2010, human-technology interaction interests both academics and industry. Scientists aim to understand how things are, whereas industry is more interested in how things should be (Saariluoma, 2010). One example of this contradiction is the field of educational technology, where many scientific promises are difficult to implement, especially among the broader community of teachers and students. A typical scenario is that, although teachers and students have access to computers, technology is not used in pedagogically relevant ways, that is, how researchers have defined as promising. Advanced pedagogical practices are often developed in research-based "light-house" projects, rather than by modifying good practices as part of a new culture of schooling. Developing sustainable pedagogical practices requires long-term commitment and close collaboration among and between teachers and researchers. Restated differently, sustainable pedagogical practices utilizing technology are not found ready-made, but emerge only from the interactions of and between practitioners and researchers. In education, and many other fields of human-technology interaction, changes in the learning and use cultures are slow to grow and to be integrated and involve long-term effort (see, e.g., the special issue of ICT and Education; Kankaanranta, 2005).

The continuous tensions between the various theoretical and methodological approaches, as well as between scientific and practical stances, swirl within a wide range of views, and beliefs abound about the role of technology in our learning society. According to the most optimistic opinions, technology plays a tremendous role in leading society toward a learning revolution. But critical views on technological hype also frame the discussions. For example, a vast discussion continues regarding the phenomenon of the so-called Net Generation students (Tapscott, 2009), or digital natives (Prensky, 2001). Many assume that this generation-born in the Internet age - can access, use, and create information and knowledge in different and more flexible ways than earlier generations. Although the ubiquitous availability and use of the latest technology enable contextualized learning experiences by making information available at any time and place, several challenges to learning must be addressed. Multitasking of information resources might lead to increased cognitive load and surface-level processing of information at the cost of coherent thinking. "Grasshopper minds," with parallel processing and a short attention span (Papert, 1994), can utilize visually organized information, but might have challenges in producing conceptually well-organized texts and solving complex problems (Carr, 2010). Growing interest in these areas has resulted in many assumptions but substantially fewer theoretical elaborations and empirical research on how Net Generation students actually learn, collaborate, and use technology. Indeed, the rapid development of technology and on-line services requires rethinking of the traditional views on human-technology interaction. The urgent need in every discipline involved in human-technology inquiry is a deep and critical analysis of the human perspective as a core part of technology development. 
Diverse and multidisciplinary approaches toward human-technology interaction are evident as well in this issue of the journal. We open the issue with papers focused on understanding the practices and innovations in work organizations. In their article, Luoma-aho, Vos, Lappalainen, Lämsä, Uusitalo, Maaranen, and Koski present the theoretical basis for a measurement system that will help organizations create and advance a more innovative climate. Their work arises from multidisciplinary research on intangible assets, drawing on the literature from disciplines such as psychology, human resources management, communication, information technology, and marketing. The factors they identified as key assets of organizational innovativeness vary from the individual to the organizational levels, and form the basis for future testing.

Koskinen, Luomala, and Maaranen continue the discussion on intangible assets in organizational innovation by focusing on ICT-related intangibles. Specifically, they attend to connectedness and organizational flexibility as enablers of innovation. Through a Delphi study, these researchers identified multiple constraints on organizational innovation and, from these, results indicators were formulated. Koskinen and her colleagues highlight the importance of ICT-related factors, but emphasize that their nature is closely related to other organizational factors and people.

The importance of the human perspective in developing work practices is emphasized in the study by Winman and Rystedt. Their study focuses on electronic patient records (EPRs) as part of medical practice. EPRs are used to improve interprofessional communication and decision making. According to their results, EPRs should not be viewed as definitive or constraining knowledge but rather flexible technologies that help to deconstruct information into patterns based on shared expectations within the work environment, and thus prestructuring a pathological reality. Yet Winman and Rystedt point to the human agent within technology usage as a crucial role. Namely, their results indicate that the members' knowledge on bridging the standardized categories in EPRs and their local meanings is a necessary prerequisite for how EPRs can support interprofessional collaboration.

The users' perspective and voice is strongly present in research on digital storytelling. Digital storytelling has been theorized as a means to disseminate the stories and voices of “ordinary” people. The paper by Hancox discusses a digital storytelling project in Australia as a means to give voice to and validate the lived realities of those marginalized and/or traumatized in societies. She concludes that the standard forms, expectations, and processes of employing digital storytelling as a method need to be revisited and reformed to address the specific needs of marginalized storytellers.

Human technology research aims to take user's perspective into account through practices such as interaction design. In line with this goal, Lehane focuses in his paper on interaction design and the attempt to make system designs intuitive. Based on his action research and grounded theory analysis, Lehane outlines categories for system acceptance surveys and research during the transitions in organizational technologies.

As the editor in chief, it is my honor and pleasure to continue the deserving work of Human Technology's founding editor, Professor Saariluoma, who stated in the inaugural issue of the journal, "Instead of intuitions, we need serious scientific analysis of human role in and interaction with technology” (p. 2). Human Technology: An Interdisciplinary Journal on Humans in ICT Environments will continue to offer an open forum for the scientists who 
wish to improve understanding through multidisciplinary research into the wide diversity of human technology topics. In that vein, the papers in this issue demonstrate the need for diverse approaches and methods, but also interaction between these approaches.

\section{ENDNOTE}

1. For more information, see http://ijcscl.org/

\section{REFERENCES}

Carr, N. (2010). The shallows: How the Internet is changing the way we think, read, and remember. London: Atlantic.

Clarà, M., \& Mauri, T. (2010). Toward a dialectic relation between the results in CSCL: Three critical methodological aspects of content analysis schemes. International Journal of Computer-Supported Collaborative Learning, 5(1), 117-136.

Kankaanranta, M. (2005). Guest Editor’s Introduction: International Perspectives on the Pedagogically Innovative Uses of Technology. Human Technology: An Interdisciplinary Journal on Humans in ICT Environments, 1(2), 111-116.

Papert, S. (1994). The children's machine: Rethinking school in the age of the computer. New York: Basic Books.

Prensky, M. (2001). Digital natives, digital immigrants, Part II: Do they really think differently. On the New Horizon, 9(6), 15-24.

Saariluoma, P. (2005). Editor's Introduction: The Challenges and Opportunities of Human Technology. Human Technology: An Interdisciplinary Journal on Humans in ICT Environments, 1(1), 1-4.

Saariluoma, P. (2010). From the Editor in Chief: Scientific and Design Stances. Human Technology: An Interdisciplinary Journal on Humans in ICT Environments, 6(2), 151-154.

Stahl, G., \& Hesse, F. (2011). Let a hundred flowers bloom; let a hundred schools of thought contend. International Journal of Computer-Supported Collaborative Learning, 6(2), 139-146.

Tapscott, D. (2009). Grown up digital: How the net generation is changing your world. New York: McGraw-Hill.

\section{Author's Note}

All correspondence should be addressed to Päivi Häkkinen

Finnish Institute for Educational Research

University of Jyväskylä

P.O. Box 35

40014 University of Jyväskylä, FINLAND

paivi.m.hakkinen@jyu.fi

Human Technology: An Interdisciplinary Journal on Humans in ICT Environments

ISSN 1795-6889

www.humantechnology.jyu.fi 